\title{
PURSUING KNOWLEDGE FOR ITS OWN SAKE AMIDST A WORLD OF POVERTY: RECONSIDERING BALOGUN ON PHILOSOPHY'S RELEVANCE \\ DOI: https://dx.doi.org/10.4314/ft.v8i2.1
}

\author{
Submission: January 30, 2019 Acceptance: May 20, 2019 \\ Thaddeus METZ, Ph.D \\ Distinguished Professor, University of Johannesburg \\ Email:tmetz@uj.ac.za
}

\begin{abstract}
In this article I critically discuss Professor Oladele Abiodun Balogun's reflections on the proper final ends of doing philosophy and related sorts of abstract, speculative, or theoretical inquiry. Professor Balogun appears to argue that one should undertake philosophical studies only insofar as they are likely to make a practical difference to people's lives, particularly by contributing to politico-economic development, or, in other words, that one should eschew seeking knowledge for its own sake. However, there is one line of thought from Professor Balogun, about philosophy being able to make life meaningful, that I argue ultimately-perhaps contrary to his intentionsentails that it can be appropriate to some degree to pursue philosophy that is unlikely to ameliorate poverty and similar social ills. My central aims in this article are to identify Professor Balogun's strongest argument against pursuing any knowledge for its own sake and to argue that an appeal to meaningfulness constitutes a strong, competing reason to seek out some of it.

Keywords: Development, Higher Education, Knowledge for Its Own Sake, Meaning of Life, Meta-philosophy, Poverty, Social Relevance

\section{Background: Theory Only for the Sake of Practice?}

Is it appropriate to do philosophy, or a similar kind of intellectual engagement, insofar as it is unlikely to make a practical difference in people's lives? When so many people are poor, unemployed, oppressed, unhealthy, uneducated, and are so particularly on the African continent, can it be justified for a scholar based there to spend his time discovering knowledge for its own sake, and for a public university to pay him to do so?

Notice that these questions are not about whether philosophy or another kind of abstract, speculative, or theoretical inquiry could help to improve the quality of people's lives. Professor Oladele Abiodun Balogun has argued - convincingly, to my mind - that such reflection not merely can make a practical difference, but often is essential in order to do so (2008a, 2013, 24, 27, 32, 51). For example, Professor Balogun points out that philosophers are particularly well positioned to advance developmental ideals (2008a, 107109), criticize ideologies (2008a, 109-110), sift through traditional beliefs and practices in order to recover promising ones and leave unpromising ones behind (2008a, 110-111, 113-114), and help orient scientific inquiry and
\end{abstract}


technological products in the service of genuine values (2008a, 112-113; see also 2013, 27-49).

I accept these points from Professor Balogun, which amount to saying that philosophers and related kinds of thinkers could do a lot of good when it comes to "the socio-political exigencies of the moment" (BALOGUN 2008a, 107). I also accept another claim from Professor Balogun, that philosophers and similar inquirers should do a lot of good in that respect, much more than they have up to now (BALOGUN 2008a, 2008b, 2013). What I still wonder about, however, is whether philosophers should only strive to do a lot of this sort of good, or whether it can be appropriate for them also to spend some time and resources theorizing for the sake of purely epistemic ends, such as understanding human nature and our world.

Concretely, is it all right for those of us in Africa to inquire into logic (say, of the mathematical sort), the philosophy of language (e.g., when it comes to the nature of linguistic reference), or metaphysics, for instance in respect of the nature of causation, numbers, or essences, when doing so is unlikely to improve people's quality of life? I accept that some aspects of these inquiries have a chance of improving people's quality of life beyond epistemic contributions. However, it is implausible to think that all aspects of them do, and insofar as intellectual enquiry is unlikely to foster socio-economic development, I label its pursuit "knowledge for its own sake." The question, then, is whether we in an African context are unjustified in pursuing some knowledge for its own sake, that is, whether we should categorically avoid engaging in any philosophy, or more broadly systematic thought, that is unexpected to help when it comes to practice. To be very concrete, should a researcher based in Africa stop publishing on whether water is essentially the intrinsic, chemical property of $\mathrm{H}_{2} \mathrm{O}$ or instead is constituted by how it relates to other beings in an ecosystem? Or should a lecturer there no longer discuss in the classroom, say, whether the universe had a temporal beginning?

Professor Balogun's writings most often suggest that it would be wrong ever to pursue knowledge for its own sake, for instance when he says that "the task of African philosophers in contemporary times should be resonantly guided by African social exigencies, especially as defined by the questionable human condition in Africa" $(2013,52) .{ }^{1}$ If that is the tasknotice he does not say "a" task-for those of us working in the African philosophical tradition or doing philosophy while living in Africa, then for us

\footnotetext{
${ }^{1}$ Professor Balogun is not the only one in the African tradition to contend that the ultimate point of knowledge should be to improve people's quality of life. He himself quotes OLADIPO (1992) and NWAKAEZE-OGUGUA (2006), and we could add, for some more examples, DOWLING and SEEPE (2003); ADAMS (2005, 144); NABUDERE (2006); and MATOLINO (2018). In a critical survey of dozens of works by African thinkers on the point of higher education, I could not find one that extolled knowledge for its own sake (METZ 2009a; see also METZ 2009b). It might be, however, that Léopold Senghor would, upon reflection, do so (see SENGHOR 1964, 47, 79).
} 
no more inquiry into what the nature of water is or whether the universe has existed forever.

However, in at least one discussion, I believe Professor Balogun provides an argumentative strategy the logic of which leaves some space for us to pursue knowledge for its own sake. According to this line of thought, philosophy is properly concerned with what Professor Balogun refers to as our "existential" status or the "meaningfulness" of our lives. I argue that prizing this value ultimately-perhaps contrary to Professor Balogun's intentionsentails that it can be appropriate to do some philosophy that is unlikely to ameliorate poverty and similar social ills.

In the next section of the article I expound what I see as three distinct arguments Professor Balogun advances against pursuing any knowledge for its own sake. In catchwords, they appeal to the particularity of social context, the concept of an educated person, and the implications of a communal ethic. I provide reason to doubt the first two rationales, but accept that the last one, which explicitly appeals to characteristically African moral values, is strong.

In the following section I address the existential orientation of some of Professor Balogun's thinking, which is relatively unique in professional African philosophy. It is only a handful of African philosophers who (when writing in English) have explicitly invoked life's meaning as a key value (e.g., SINDIMA 1989, 544-548; DZOBO 1992, 227-230; GBADEGESIN 1991, 58; IGBAFEN 2017). ${ }^{2}$ I work to flesh out a plausible approach to what makes life meaningful and to show that it supports some kinds of intellectual inquiry that are not expected to make a practical difference in people's lives.

In a further section, I weigh up Professor Balogun's moral argument against knowledge for its own sake against my meaning argument for it, arguing that the best understanding of morality includes a concern to advance meaning in people's lives. It follows that there is moral reason of some strength to promote understanding of the human condition apart from any further, beneficial consequences.

In the concluding section of the article, I note some limitations of the argumentation advanced here. I point out that, given the current state of the debate, it is not yet clear that it was indeed right for me to have composed this article - itself an instance of knowledge for its own sake, reflection that is unlikely to improve anyone's quality of life.

\section{Questioning Knowledge for Its Own Sake}

In Professor Balogun's corpus I detect three distinct arguments against the view that a philosopher (or similar inquirer) should ever seek out knowledge that is unlikely to improve people's quality of life, non-epistemically understood principally in terms of politico-economic development. They

2 For some of the few in African philosophy who have expressly and systematically concerned themselves with life's meaning, see ATTOE (unpublished); and METZ (unpublished). 
appeal respectively to the particularity of social context, the concept of an educated person, and the implications of a communal ethic, and in this section I address them in this order, providing reason to doubt the first two arguments but also to think that the third is formidable and not easily overcome.

The most salient argument against knowledge for its own sake in Professor Balogun's writings involves an appeal to social context. The basic idea is that the function philosophy should serve depends on the society in which it is located. For someone engaging with the philosophy that has grown out of African culture and is set in a certain environment, or for a philosopher who is living with Africans, the form that her philosophy should take should be determined by that culture and environment. ${ }^{3}$ Professor Balogun has appealed to this consideration in at least two major essays to draw the conclusion that philosophy in Africa should have a strictly practical orientation:

The point here is that philosophy develops from context, and no philosophy exists in a vacuum.... The dismal condition of living in Africa, marked by bad governance, poverty, conflict, lack of scientific knowledge, under-development, and injustice, is among the sociopolitical exigencies that should define the philosopher's task on the continent....The duty of the philosopher, then, is to theorize on how to reorder the political values and institutions for the reconstruction of the present and determine how to design a new future. (BALOGUN 2008a, 107; see also 114)

To affirm philosophy as a "social-epochal expression" is to express the anti-thesis of the perennial nature of philosophy....In relation to the African situation, there is a dismal condition of living in all spheres of social structure....(I)s a philosophy rooted in an African culture a means to an improved human condition in contemporary times or an exercise in pure abstraction?....In as much as the content and direction of every philosophy is historically and socially conditioned, philosophy in Africa should be resonantly guided by African social exigencies. (BALOGUN 2013, 15, 21, 23, 30; see also 29, 33)

This reasoning suggests that it could in principle be right for those outside the African context to pursue some knowledge for its own sake. Perhaps it is appropriate for European philosophers to undertake some inquiries unlikely to

${ }^{3}$ By "African philosophers," "philosophy in Africa," and similar phrases, I presume that Professor Balogun means either someone working in the African tradition but who might not be living on the continent (one doing African philosophy), or someone living on the continent even if not doing African philosophy (one doing philosophy in Africa). I gather he means to exclude a person of African descent doing, say, Confucian philosophy in China. 
improve anyone's quality of life, say, because European society is politicoeconomically well developed or because European people appreciate that sort of reflection. However, for Professor Balogun, it would be wrong for African philosophers to do so-notice how he speaks of "the" (not "a") task and "the" duty of the philosopher in Africa to advance development. ${ }^{4}$

Notice that Professor Balogun is not suggesting that philosophers stop doing philosophy and become political activists. He is clear that the abstraction, the questioning, and the theory that are characteristic of philosophy should continue, but that they should be put to good use for improving people's quality of life (e.g., 2008a, 112, 114-115; 2013, 52). In fact, Professor Balogun believes that often the best way for philosophers to improve people's quality of life is not to aim directly for that practical outcome, and instead to concentrate on intellectual matters. ${ }^{5}$ Note that this belief does not mean Professor Balogun approves of seeking out knowledge that is in fact unlikely to improve people's quality of life or thinks that epistemic considerations can be sufficient to pursue a certain sort of study.

Similarly, Professor Balogun need not be understood as maintaining that all logicians, philosophers of language, and metaphysicians should switch to becoming moral and political philosophers. Instead, I presume the present argument would entail that they should just do the sort of logic, philosophy of language, and metaphysics that would help to "reorder the political values and institutions". That could well include critical thinking, reflecting on the nature of slurs and other insults, and inquiring into social ontology.

My concern with this argument is that just because culture and environment more broadly do influence philosophical reflection in certain ways, it does not follow that they should. After all, consider apartheid society in South Africa. Surely philosophers there should not have done whatever they could to help impose Afrikaaner and more generally Western culture and to facilitate the neglect, if not denigration, of indigenous cultures. Apartheid society influenced "the content and direction" of the philosophy done in South Africa at the time, but it did so in undesirable ways. What this example is meant to show is that it is not necessarily true that a philosophy should be molded by its social context or by the dominant forces in it.

Indeed, philosophy has an important task of evaluating the culture and environment in which it is located, not uncritically accepting them. That is, in fact, a point that Professor Balogun clearly accepts in his writings - the title of his inaugural lecture, "Philosophy in an African Culture: A Light in the Darkness" is meant to point out that not all aspects of culture merit retaining. However, I believe the implication of the point is that we cannot directly infer what the function of philosophy should be from the fact that it is "historically and socially conditioned," or from the fact (if it is one) that there is no pure reason operating independently of empirical influences. We also have to think,

${ }^{4}$ However, there are times when he speaks more loosely, e.g., of the "primary" task of African philosophers (BALOGUN 2008a, 106).

${ }^{5}$ This somewhat stronger position was expressed in conversation with the author. 
philosophically, about whether that society has been structured justly and otherwise desirably, and about what the proper role of philosophy is in that society. We have to determine which "social exigencies" count, or perhaps what count as "social exigencies" in the first place.

So, Professor Balogun needs additional premises, I submit, beyond what have been mentioned so far, in order to draw the conclusion he wants. In particular, it would be useful for him to have some moral or other normative propositions with which to specify the proper role of philosophy in a given social context. Although I do not see that he is explicit about ethical claims in his work specifically on the relevance of philosophy (BALOGUN 2008a, 2013), he is in other essays, and it would be revealing to draw on them, as I do below.

A second argument from Professor Balogun's body of writings advanced to rebut the propriety of pursuing knowledge for its own sake appeals to the concept of an educated person. The core idea is that an educated person is essentially a good citizen, not a bookish recluse.

In the African culture, the concept of an "educated person" is broader since there is no such distinction between the "educated person" and the "ideal citizen", as we have in Western culture....(A)fter an educational experience (whether formal, informal or non-formal), it is expected that the educated should be able to turn his or her acquired skill and knowledge into a citizenship service....(The) emphasis on the intrinsic value of knowledge and other related experiences shows again, the point of divergence between the African understanding of an educated person and the Western conceptual model. (BALOGUN $2008 b, 122,123,124)$

Professor Balogun's claim is that, in contrast to a Western conception of the educated person as one who is isolated, reads a lot, has completed exams, has acquired certificates from an authority, and values knowledge intrinsically, in the African tradition an educated person is essentially, amongst other things, socially engaged, able to speak to people, and puts her knowledge to use for others. ${ }^{6}$

Although Professor Balogun speaks here of what education means for indigenous African society in contrast to the modern West, he can be sensibly read as making a stronger claim, namely, that social contribution is inherent to the best understanding anywhere of what a truly educated person is. For one, Professor Balogun forcefully notes that education is not the mere apprehension

${ }^{6}$ In another essay Professor Balogun critically reflects on the views of two African theorists of education, and advises combining the one that "has the potential to open African societies to the wider horizon of science and technology" with the other that "has the capacity to inculcate into pupils the intellectual, moral and democratic values prerequisite for good citizenship" (BALOGUN 2009a, 71). The strictly pragmatic orientation is clear. 
of facts demonstrated by passing written assessments in a dedicated school building, for "there are some people in both Western and African cultures who have never seen the four-walls of a school, to receive formal education, yet they are educated" (BALOGUN 2008b, 124).

For another, Professor Balogun's point is strengthened by invoking the concept of wisdom, as he occasionally does $(2008 \mathrm{~b}, 122,124)$ and as Kwasi Wiredu (2004, 18-19) has. An education, properly understood, is plausibly identified as the development of wisdom, which has an essentially practical dimension. A wise person is intuitively captured by the way Professor Balogun describes an educated person: "one who shows evidence of a well-integrated personality, meaning being economically prudent, socially and politically competent, morally acceptable and intellectually and culturally sophisticated" (BALOGUN 2008b, 124).

It is therefore not merely those inclined toward indigenous African worldviews who should take seriously the suggestion that a person is educated insofar as she is wise or is a good citizen. If we now add the premise that the proper function of a public university is to develop educated people, which certainly seems right, then we can draw the conclusion that philosophy and knowledge pursuit more generally there must advance good citizenship, and not be pursued for their intrinsic, epistemic value.

It is undoubtedly true that it is possible to be an educated person without having acquired, let alone valued, knowledge for its own sake of the sort I am discussing in this article. It is also undoubtedly true that one would be an educated person if one were the sort of person that Professor Balogun describes. In brief, knowledge for its own sake is not necessary for education, while good citizenship is sufficient for education. I am even inclined to accept that good citizenship is necessary for being a fully (or genuinely) educated person. Professor Balogun advances all these claims, and they are convincing.

It does not follow from these claims, however, that education is not constituted in part by knowledge for its own sake. That is, it could still be the case, for all that has been said so far, that one would be more educated to some degree, the more one knew about abstract, speculative, and theoretical matters that are unlikely to improve people's quality of life.

And that, I submit, is true. It is true that one way to be educated is to learn about, say, the nature of causation or the origin of the universe. It is not the only way to be educated, and one is not completely (or even adequately) educated if that is all one knows. However, some knowledge for its own sake is intuitively part of what it means to be educated. After all, suppose a philosopher or cosmologist came to discover with substantial evidence what the origin the universe was - it would be right for his university to honor him in virtue of his education (and, furthermore to do so not insofar as the discovery is likely to improve people's health, advance democracy, or anything else pragmatic, on which see METZ 2010, 541-543).

Now, if one sort of education consists of knowledge for its own sake, then we cannot appeal merely to the concept of an educated person in order to determine whether it is right for those at a public university to pursue 
knowledge for its own sake or not. There are different types of education, some oriented toward practical ends and others toward epistemic ones, meaning that we must choose which types are the most important or otherwise merit pursuit. For that (as with the first argument explored above) some moral or other normative considerations would be particularly useful for prioritizing the various conceptions of an educated person.

That brings me to the third argument against knowledge for its own sake that is suggested by Professor Balogun's writings. This argument is explicitly a moral one, and so promises to fill in the gaps that I maintained are present in the previous two arguments, regarding how a philosopher should respond to social context and which sort of education is most desirable. Basically, according to the present argument, one plausible strand of African thought about morality entails that it would be immoral to devote time, money, and other resources to inquiry that is unlikely to make a practical difference in people's lives.

In some of his works, Professor Balogun draws on a relational interpretation of Yoruba ethics to address contemporary issues. For example, in one article he says, according to the Yoruba people, "Social crimes are directed against individuals who ultimately upset the societal harmony" (BALOGUN 2009b, 47; see also mention of "communalism" and "equilibrium" in BALOGUN 2013, 37, 39). Supposing that social crimes are invariably ways of treating others immorally, we can derive the principle that an act is immoral (at least characteristically) in virtue of being discordant, that is, disrupting harmonious relationships.

In another article, Professor Balogun sketches a moral perspective with which to evaluate Nigerian politics. Here he says of Yoruba ethics that it is "characterized as being community-centred. The communal values of the Yoruba are anchored in the notion of common will (the common or public interest)" (BALOGUN 2015, 7). Like some other interpretations of the common good, Professor Balogun maintains that it consists of a balance between the interests of the individual and those of others in her society (BALOGUN 2015,7) and that it includes "the self-determination of a people" (BALOGUN 2015, 9). Elsewhere in this essay Professor Balogun speaks of moral paradigms including "respect for human life and dignity, fostering communal humane bonds, and formation of virtuous habits" (BALOGUN 2015,10 ), and he says that "society should emphasize the value of hard work, diligence, self-reliance, and the importance of acquiring character traits such as honesty and social responsibility" (BALOGUN 2015, 10).

Now, here is the rub: it appears that none of the above descriptions of morality entails that one should pursue knowledge for its own sake, whereas they do tend to prescribe doing what would improve people's quality of life. First off, it might be that addressing the nature of causation and the origin of the universe would be, if not discordant, then at least not sufficiently harmonious, in the sense of inappropriately isolating oneself and failing to be concerned with others' well-being. Second, the common good would not be adequately advanced by pursuing knowledge for its own sake, since, by 
definition, it is unlikely to improve people's health, advance justice, reduce poverty, and the like. Third, people will be in no greater position to "take their lives....into their own hands" (BALOGUN 2015,9) if academics study certain types of logic, philosophy of language, or metaphysics; these inquiries would not support democratic self-governance. Fourth, it does not appear that respect for human life and its dignity demands the study of theory that will make no practical difference, whereas such respect instead seems to prescribe doing what it takes to save lives. Fifth, the specific virtues that Professor Balogun mentions, viz., of hard work, self-reliance, honesty, and social responsibility, are more likely to be developed and manifested in the context of pursuing pragmatic knowledge, not knowledge for its own sake.

I believe this is the strongest argument in Professor Balogun's writings for thinking that it would be wrong for an African philosopher or philosopher in Africa to do philosophy of a sort that is not socially relevant. Notice how appealing to these moral considerations would strengthen the other two arguments explored above. With regard to the idea that every philosophy is a product of its culture and environment, the present rationale entails that a philosopher should work to improve his society in the morally relevant ways above. And when it comes to which sort of education would be most desirable to advance, the present rationale entails that member of a university ought to promote the sort essential to being a good citizen.

Before evaluating this argument, I expound what I see as another, existential line of thinking in Professor Balogun's work, one that, I contend, upon reflection supports an opposite conclusion to the effect that some knowledge for its own sake is appropriate. After spelling out this reasoning in support of knowledge for its own sake, I weigh it against Professor Balogun's moral rationale against it.

\section{Knowledge for Its Own Sake as a Source of Meaning in Life}

The primary message that I get from reading Professor Balogun's philosophical reflections is that philosophy and similar kinds of inquiry should invariably serve a practical function, but there is one strand of reasoning that is different, at least upon some refinement. There are occasions when Professor Balogun uses the language of "existential" or "meaningful" matters, which terms differ from the mention of "social" or "political" interests. In this section, I first indicate what Professor Balogun says about the former matters, and then appeal to them to develop a clear and promising rationale for thinking that some knowledge for its own sake would be appropriate to pursue.

It is a striking fact about works in African philosophy that there is very little written specifically about what can make life meaningful. Professor Balogun is in fact one of the few to mention the concept explicitly, and he does so particularly in his inaugural lecture (2013). Professor Balogun does not explicitly define "meaningfulness" and cognate terms, but I presume we both have in mind conditions of life for which reactions of esteem or admiration would be fitting, or that involve purposes that particularly merit pursuit and are higher than feeling pleasure or satisfying desires (on which see, 
e.g., METZ 2013, 24-35). Looking back on your life from your deathbed, what was it about your life in which you could reasonably take substantial pride, or what was worth more than the mental well-being you enjoyed? Answering those questions involves making judgments of meaning in life.

Most often Professor Balogun maintains that the under-development in the political-economic realm or otherwise poor quality of life so widespread in Africa is what renders life meaningless, so that meaning would, conversely, come from practically helping others live better lives (e.g., 2013, 22-23, 27, $28,39,46)$. However, there are other places where Professor Balogun seems to say that considerations of meaning in life are not exhausted by social matters and that philosophers should address considerations of meaning as apparently distinct from them. Consider the following remarks:

(C)ulture in a broad dimension essentially entails our general mode of making meaning out of existence and ways of living....(E)very philosophy is a philosophy of culture. (BALOGUN 2013, 7, 18)

I however consider philosophy to be indispensably relevant not only to society, but also to meaningful human existence....Philosophy involves a rational inquiry into how we make meaning of existence in human culture. (BALOGUN 2013, 27)

(T)he apparent disinterestedness of funding agencies in conceptual, reflective, normative or speculative researches which are common places in the Humanities should be overcome in order to realize, in the near future, the existential implications of researches in philosophy. (BALOGUN 2013, 53)

The first and second quotations say that philosophy is squarely about how to make life meaningful, while a plain reading of the second quotation also suggests that social matters are one thing and that meaning is another (presumably broader) thing, and the third quotation contends that philosophy, insofar as it addresses issues of meaning, merits funding (and surely other resources, too). These ideas occasion awareness of the position that one major point of philosophy is to inquire into and advance meaning in life, which is not reducible to social matters and merits support. I presume that if meaning in life is not reducible to satisfying people's interests, and that philosophy should concern itself with meaning, then there is something of epistemic value about philosophy that merits pursuit.

I am not sure that this is what Professor Balogun had in mind, and, indeed, I doubt it, given how much more frequently he associates what is meaningful with what would improve people's quality of life. His dominant perspective is clearly expressed here:

The view that philosophy is purely theoretical without influence on practical or existential human existence is problematic, because philosophers shape the society and indeed the future by changing 
people's beliefs and habits of thought, which in turn affect their actions....Without philosophical consideration, life is without meaning. (BALOGUN 2013, 27)

In contrast, in the rest of this section I argue that the appeal to meaningfulness, as a concept distinct from the concepts of social context, educated person, and moral virtue, grounds a strong defense of the idea that academics should devote some energy to pursuing certain kinds of knowledge for its own sake. Roughly, although much meaning surely comes from action done for the betterment of society, not all of it must; some meaning can come from cognition alone.

I begin to support the idea that meaning in life is not exhausted by improving others' quality of life with some non-epistemic examples, before turning to epistemic ones. Probably most long-standing cultures around the world do, with Professor Balogun, place helping interpersonal relationships at the center of meaning in life. However, many will have intuitions that there are additional ways to confer some meaning on one's existence. For a first cluster of examples, consider some virtues that do not seem essentially otherregarding. Think of courage, strength of will, patience, creativity, and selflove. Someone who exhibits these traits, or who at least has worked to cultivate them, plausibly has grounds for esteem, that is, for feeling good about herself, and others would have good reason to admire her for them, which are reliable markers of meaningfulness.

The positive responses many of us are inclined to have toward someone who exhibits these kinds of traits are not due merely to the fact that they might prompt her to treat others morally. Instead, they seem desirable to many even when they have no bearing on others' welfare. One way to see this is to conduct a thought experiment. Imagine a person shipwrecked on a deserted island who initially believes against all the evidence that he will be rescued soon, runs in terror from the wild warthogs, makes do with an undecorated cave for shelter, gets addicted to an indigenous plant, and hates himself. Now, in contrast, imagine that this person has successfully accepted that rescue is unlikely, striven to battle the warthogs with courage, fashioned a shelter using trees in a creative way, shaken off his addiction, and become compassionate toward himself. Surely, the meaningfulness of his life has increased over time, despite not having been in a position to help others.

One plausible way to sum up many of these sources of meaning is in terms of practical reason. A number of them are ways of judging in the light of rational reflection and then choosing on that basis, as opposed to letting one's feelings and emotions govern one's life without mediation. Now, if practical reason can be a source of meaning in life, considered apart from the function of improving others' quality of life, then so can theoretical reason.

Before considering how cognition in itself can be a source of meaning, note first how it can sometimes undercut meaning. There is something sad about members of Heaven's Gate, a cult in the United States whose members killed themselves in the belief that only suicide would take them to a spacecraft trailing the Hale-Bopp Comet that would, in turn, carry 
them to paradise. Or consider schizophrenics who incorrectly think that the devil is controlling their lives. The reaction of pity that I presume the reader has is well explained (in part) by the idea that false beliefs about the fundamental nature of our environment reduce the meaningfulness of a life. Of course, the false beliefs in these cases are expected to lead to bad choices, but the lack of meaning, I submit, is not simply a function of the latter. In addition, a person's life is less meaningful to some degree, the more he fails to understand, and especially the more he is misguided about, the fundamentals of the world in which he lives.

Conversely, acquiring true beliefs about the basic nature of reality plausibly enhances meaning in life. It is this principle that best explains the importance of Albert Einstein's life for having made discoveries about light, energy, gravity, space-time, and black holes. It is true that these discoveries have made some practical differences, including enabling scientists to position satellites accurately. However, these influences on people's quality of life fail to capture the significance of Einstein's insights adequately. Even before anyone could foresee how they would benefit people, many would have deemed them meaningful simply by virtue of clarifying so much about how the physical world operates. Now we know that space and time are not fields that are uniform across the universe, but instead that they are affected by the mass of objects, so that, near extremely heavy bodies, space can warp and time can slow down. Similar remarks apply to the insights of Copernicus; his life was plausibly meaningful for having reasonably posited that the earth revolves around the sun, and not the other way around.

For yet another example, consider that Charles Darwin's systematic defense of human evolution is important not so much because it has fostered politico-economic development, if it did that at all, but more because of what it has taught us about the origin and nature of our species. It is one thing to think that God created us as a species distinct from other species all in one go, and another to think that we evolved from other hominids through a series of mutations over millions of years (a process that may have been started by God). I think that, if you believe the former is true, then you have false beliefs (or at least unjustified ones in the face of a compelling fossil record) - but set that matter aside. We can at least agree that whichever of us has knowledge of the basic features of human race has a somewhat more meaningful life than the one who holds false or unjustified beliefs about that, and simply in virtue of the object of the beliefs.

It is not just physics and biology that offer meaningful revelations about the nature of ourselves, our world, and our place in the world; philosophy probably does, too. For example, it is important to have learned that David Hume was in all likelihood incorrect that causation is reducible to contiguity. For another example, it is significant for Saul Kripke and Hilary Putnam to have made the strong case that the way our words refer to physical things is not by the latter exhibiting features we mentally associate with the former, but instead through certain "causal" processes. For a third, although conclusively ascertaining "where morality comes from," i.e., whether it is a 
supernatural, non-natural, or natural property, might not change the content of our moral beliefs (and hence not influence our decisions), it would be an important discovery all the same, revealing something deep about our species.

In sum, I agree with Professor Balogun that one major point of doing philosophy and similar kinds of inquiry is to foster meaning in people's lives. However, where I probably disagree with him is about how philosophy can confer meaning. Most often he suggests that philosophy's way to make people's lives meaningful is by facilitating beneficent action, for instance, by contributing to social development. However, I have argued that there are additional ways for philosophy and other types of knowledge pursuit to enhance meaning, namely, simply in virtue of epistemic considerations. Thinking about the right sort of thing (roughly, what is fundamental to human beings and our world) and in the right sort of way (roughly, by understanding) itself can be a real source of meaning. If so, then there is a strong case in favor of seeking some knowledge for its own sake.

This rationale in favor of knowledge for its own sake differs from other, more prominent ones that have been offered. For example, some have argued that knowledge that appears unlikely to make a practical difference to people's lives often ends up doing so in unforeseeable ways (e.g., MAKGOBA 1998, 47; IKPE 2010, 534-535; FLEXNER 2017), while others have maintained that pursuing knowledge for its own sake makes one more inclined to seek out the truth and hence stand up to power in the service of justice (e.g., HIGGINS 2000). I believe these are weak arguments (see METZ 2009b, 2010), but, rather than try to show that here, I note that an appeal to meaning, suggested by Professor Balogun's work, is under-developed and promising as a way to explain why some thinking is good in itself. ${ }^{7}$

\section{Meaning versus Morality?}

Here is where the debate stands. On the one hand, Professor Balogun believes that moral values are squarely a function of treating others respectfully and in ways that are likely to make their lives go well. These values, which include promoting the common good and facilitating self-governance, on the face of it provide no reason to pursue knowledge for its own sake at a public university and instead to engage in only that inquiry that is likely to make a practical difference. On the other hand, Professor Balogun and I both think that one proper job of philosophical and related kinds of thinking is to foster meaning in life, while I have further argued that one way that they can do so is simply in virtue of the sort of thought involved. How, then, to adjudicate between these two positions? What in the final analysis should an academic study, given the conflict between the two values of morality and meaning?

I seek to reduce some of the tension by offering Professor Balogun a reason to revise his morality, if he does not already accept the following. He

${ }^{7}$ Cf. METZ (2013, 229-230, 2018, 177). 
clearly believes, as I do, that meaning is an important value that can be exhibited in a person's life. If so, then I submit that an attractive account of morally right action would not disregard it. In addition to advancing people's well-being (happiness) and their personhood (virtue), a plausible morality would instruct an agent to promote meaning in others' lives. That goes not merely at the individual level, but also at the collective, where organizations such as governments and businesses are in such a large position to enhance, or conversely detract from, what makes life meaningful (for some discussion, see METZ 2016).

Yoruba ethics, and African moralities more generally, are not normally understood in this way. Usually the focus of a sub-Saharan account of right action is on people's needs, understood either biologically and psychologically, on the one hand, or socially, on the other. My proposal is that an additional sort of human need, under-theorized in the African tradition, is existential. What we characteristically value is not merely physical and mental health and self-realization through service to society; in addition, we tend to want to accomplish things that merit esteem and admiration, and ideally by making differences that will outlive us, say, in the form of children, traditions, works of art, and perhaps even a philosophy essay.

If people's dignity gives us moral reason to go out of our way to help them, then the help should include assistance in achieving what is particularly worth having in life, which includes meaning. And if part of caring about people's good is indeed a matter of enabling them to live meaningfully, and if that includes understanding certain objective truths about humanity and the world in which we live, then it follows that we have some reason to promote some knowledge for its own sake. There is moral credit that goes to those who advance meaningful understanding of the general human condition, not merely to those who address "African social exigencies" (BALOGUN 2013, 52) or "the socio-political exigencies of the moment" (BALOGUN 2008a, 107), admittedly important as these are.

\section{Conclusion}

Having shown that there is some moral reason for philosophers (and other inquirers) to pursue some knowledge that is unlikely to be relevant to the current political-economic situation in Africa is not yet to answer conclusively the questions posed at the start of this article. Recall one of them: should a lecturer stop discussing with students whether the universe had a temporal origin? Even if learning about the origin of the universe were meaningful, and hence even if there were some moral reason to strive for that, Professor Balogun might suggest that there would be more moral reason for philosophers to address the current political-economic situation in Africaperhaps precisely because it would promote more meaning to do so.

Resolving this issue, about the various degrees of meaning available from various kinds of scholarly inquiries, is beyond the scope of this article. Its main aim has been to evaluate Professor Balogun's arguments against knowledge for its own sake, and to weigh up the strongest one against a line of 
thought that appears promising as a way to defend such knowledge, viz., the idea that one major point of philosophy is to foster meaning in people's lives by advancing understanding the general human condition. I close this article by mentioning some additional issues that need to be discussed elsewhere in order to draw the firm conclusion that although philosophers can and should do more than they have to redress the poor human condition in Africa, that is not all they should do.

In order to know with real confidence that I should have written this very article-which is unlikely to make a (positive) practical difference in people's lives! - we need to address the following issues in some depth. Can philosophers ever be in a position to save lives with their inquiries, and, if so, would that be the most meaningful sort? Even if there were a sort of philosophical knowledge that would be most meaningful for saving lives, how likely is it that we would discover it and that politicians (and other nonphilosophers) would put it to proper use? Are we instead much more likely to develop meaningful knowledge for its own sake, and, if so, might it therefore be most rational all things considered to pursue it? How do communal ties figure into the decision of what to study, in terms of either morality or meaning? For example, should one aid other colleagues who are pursuing knowledge for its own sake by helping them in their quest, or should one give to one's society knowledge that would benefit it politico-economically? If one owes both groups to some extent, which one has the weightier claim, and how does that compare to one's ability to benefit lots of foreigners who are even worse off? How much does it matter if people outside of academe cannot easily understand the sort of philosophical knowledge that is meaningful in itself? It would of course be most meaningful if they could and did understand it, but might their lives be somewhat more meaningful if humanity in general had access to this kind of knowledge, in the way that humanity can access quantum mechanics even if few can ever understand it? Finally, even if being a philosopher can foster some meaning in people's lives, either practically or theoretically, would a change of career, to something more practical, be likely to foster much more meaning?

Although these questions have yet to receive thorough answers from philosophers, it is an important virtue of Professor Balogun's work, one of the few in the African tradition to consider issues of meaning explicitly, that it has occasioned awareness of them. As the reader can tell, I am inclined to think that his research is worth thinking about for its own sake, or else I would not have composed this article. I hope that, upon having reached the end of it, the reader agrees.

\section{Acknowledgments}

I am grateful to Professor Oladele Balogun and others affiliated with the Olabisi Onabanjo University for their oral engagement with a lecture based on a prior draft of this article. I also appreciate having received written comments from an anonymous referee for Filosofia Theoretica. 


\section{Relevant Literature}

1. ADAMS, N. D. "Reshaping Some of the Conceptual Orientations of Lifelong Learning in South Africa through an African Philosophy of Education," [African(a) Philosophy of Education: Reconstructions and Deconstructions, Yusef WAGHID Ed.], pp140-163, 2005. Stellenbosch: Department of Education Policy Studies, Stellenbosch University. Hardback.

2. ATTOE, Aribiah. [An Inquiry into African Conceptions of the Meaning of Life], 2019. PhD Thesis, University of Johannesburg. Unpublished.

3. BALOGUN, Oladele Abiodun. "Philosophy: What Social Relevance?" [Philosophia Africana], pp103-116, 2008a. Vol 11. No 2. E-book.

4. _. "The Idea of an 'Educated Person' in Contemporary African Thought," [Journal of Pan-African Studies], pp117-128, 2008b. Vol 2. No 3. E-book.

5. _ . "A Philosophical Comparison of the Educational Thoughts of Obafemi Awolowo and Tai Solarin." [Thought and Practice], pp 6172, 2009a. Vol 1, No 2. E-book.

$6 . \quad$. "A Philosophical Defence of Punishment in Traditional African Legal Culture: The Yoruba Example," [Journal of Pan-African Studies], pp43-54, 2009b. Vol 3. No 3. E-book.

$7 . \quad$. [Philosophy in an African Culture: A Light in the Darkness $\overline{\left(68^{\text {th }}\right.}$ Inaugural Lecture at Olabisi Onabanjo University), 2013. AgoIwoye: Olabisi Onabanjo University Mass Communication Press. Ebook.

8. . "Ethical Revolution and Development in the Nigerian Democratic Space," (Annual Distinguished Faculty Lecture of the Faculty of Humanities and Culture at Osun State University, Ikire Campus), 2015.May 2019. Web.

9. DOWLING, Dolina and SEEPE, Sipho. "Towards a Responsive Curriculum." [A Tale of Three Countries: Social Sciences Curriculum Transformations in Southern Africa, Piet NAUDÉ and Nico CLOETE Eds.], pp41-53, 2003. Lansdowne: Juta and Co Pty Ltd. Paperback.

10. DZOBO, Noah. "Values in a Changing Society: Man, Ancestors, and God." [Person and Community, Kwasi WIREDU and Kwame GYEKYE Eds.], pp223-240, 1992. Washington, DC: Council for Research in Values and Philosophy. Paperback.

11. FLEXNER, Abraham. [The Usefulness of Useless Knowledge], 2017. Princeton: Princeton University Press. Hardback.

12. GBADEGESIN, Segun. [African Philosophy], 1991. New York: Peter Lang. Paperback.

13. IGBAFEN, Monday. "Human Life and the Question of Meaning in African Existentialism," [Themes, Issues and Problems in African 
Philosophy, Isaac UKPOKOLO Ed.], pp237-254, 2017. New York: Palgrave Macmillan. Hardback.

14. HIGGINS, John. "Academic Freedom in the New South Africa." [Boundary 2], pp97-119, 2000. Vol 27. No 1. E-book.

15. IKPE, I. B. "Beyond Relevance: In Praise of Useless Knowledge," [South African Journal of Higher Education], pp525-537, 2010. Vol 24. No 4. E-book.

16. MAKGOBA, Malegapuru. W. "South African Universities in Transformation: An Opportunity to Africanise Education," [Black Perspective(s) on Tertiary Institutional Transformation, Sipho SEEPE Ed.], pp42-62, 1998. Florida Hills, South Africa: Vivlia Publishers and the University of Venda. Paperback.

17. MATOLINO, Bernard. "The Shaping of the Future of African Philosophy," [Method, Substance, and the Future of African Philosophy, Edwin ETIEYIBO Ed.], pp335-353, 2018. New York: Palgrave Macmillan. Hardback.

18. METZ, Thaddeus. "The Final Ends of Higher Education in Light of an African Moral Theory," [Journal of Philosophy of Education], pp179-201, 2009a. May 2019. Vol 43. No 2. Web.

19. . "Higher Education, Knowledge for Its Own Sake, and an African Moral Theory," [Studies in Philosophy and Education], pp517-536, 2009b. May 2019. Vol 28. No 6. Web.

20. . .A Dilemma regarding Academic Freedom and Public Accountability in Higher Education," [Journal of Philosophy of Education], pp529-549, 2010. May 2019. Vol 44. No 4. Web.

21. _. [Meaning in Life: An Analytic Study], 2013. Oxford: Oxford University Press. Hardback.

22. _. "Meaning in Life as the Right Metric." [Society], pp294-296, 2016. May 2019. Vol 53. No 2. Web.

23. _. "An African Theory of the Point of Higher Education: Communion as an Alternative to Autonomy, Truth, and Citizenship," [Contemporary Philosophical Proposals for the University, Aaron STOLLER and Eli KRAMER Eds.], pp161-186, 2018. New York: Palgrave Macmillan. Paperback.

24. __ "African Conceptions of Meaning in Life: Exposition, Reconstruction, and Critique," Unpublished.

25. NABUDERE, Dani. "Towards an Afrokology of Knowledge Production and African Regeneration," [International Journal of African Renaissance Studies], pp7-32, 2006. Vol 1. No1. E-book.

26. NWAKAEZE-OGUGUA, Ikechukwu. "The Tragedy of Pseudodemocracy and Social Disorder in Contemporary Africa: Any Philosophical Rescue?," [Philosophy and Africa, Ike ODIMEGWU Ed.], 2006. Amawbia: Lumos. Paperback.

27. OLADIPO, Olusegun. [The Idea of African Philosophy: A Critical Study of the Major Orientations in Contemporary African Philosophy], 1992. Ibadan: Molecular Publications. Paperback. 
28. SENGHOR, Leopold [On African Socialism], 1964. New York: Frederick A Praeger, Publisher. E-book.

29. SINDIMA, Harvey. "Community of Life," [The Ecumenical Review], pp537-551, 1989. Vol 41. No4. E-book.

30. WIREDU, Kwasi. "Prolegomena to an African Philosophy of Education," [South African Journal of Higher Education], pp17-26, 2004. Vol 18. No1. E-book. 